\title{
The perfusion of cisplatin and cisplatin structural analogues through the isolated rat heart: The effects on coronary flow and cardiodynamic parameters
}

\author{
Isidora M. Stojic ${ }^{1}$, Vladimir Lj. Jakovljevic ${ }^{2,3}$, Vladimir I. Zivkovic ${ }^{2}$, Ivan M. Srejovic ${ }^{2}$, Tamara \\ R. Nikolic ${ }^{1}$, Jovana N. Jeremic ${ }^{1}$, Nevena S. Jeremic ${ }^{1}$, Dragan M. Djuric ${ }^{4}$, Katarina G. Radonjic ${ }^{1}$, \\ Milica Labudovic-Borovic ${ }^{5}$, Zivadin D. Bugarcic ${ }^{6}$, Jovana Bogojeski ${ }^{6}$ and Slobodan S. Novokmet ${ }^{1}$ \\ ${ }^{1}$ Department of Pharmacy, Faculty of Medical Sciences, University of Kragujevac, Serbia \\ ${ }^{2}$ Department of Physiology, Faculty of Medical Sciences, University of Kragujevac, Serbia \\ ${ }^{3}$ Department of Human Pathology, 1st Moscow State Medical University IM Sechenov, Moscow, Russia \\ ${ }^{4}$ Institute of Medical Physiology "Richard Burian", Faculty of Medicine, University of Belgrade, Belgrade, Serbia \\ ${ }^{5}$ Institute of Histology and Embryology “Aleksandar DJ. Kostic" Faculty of Medicine, University of Belgrade, Belgrade, Serbia \\ ${ }^{6}$ Department of Chemistry, Faculty of Science, University of Kragujevac, Kragujevac, Serbia
}

\begin{abstract}
The therapeutic use of cisplatin for the treatment of solid tumours is associated with organ toxicity. Amongst those, the cardiotoxicity is an occasional but very serious and severe side effect. To prevent or reduce these negative effects, many cisplatin analogues have been synthesized and evaluated in terms of being a less toxic and more effective agent. In present study, we examined the effects of cisplatin and its three analogues in the isolated rat heart to determine whether changes in the structure of the platinum complexes (changing of carrier ligands - ethylenediamine; 1,2-diaminocyclohexane; 2,2':6,2'-terpyridine) can influence their cardiotoxic effects. The results of our research indicate that the introduction of aromatic rings in the structure of the platinum complexes has a negative influence on the heart function. Conversely, the other two examined complexes had less negative effects on heart function compared to cisplatin. Our findings may be of interest for a possible synthetic strategy of introducing a carrier ligand that will exert a less cardiotoxic effect.
\end{abstract}

Key words: Cardiac function - Cardiotoxicity - Cisplatin - Isolated-perfused heart - Metal toxicity - Platinum(II) complexes

\section{Introduction}

Cis-diaminedichloroplatinum(II) (cisplatin - CDDP) is a first generation antitumour agent with a proven clinical efficacy in the treatment of solid tumours. However, drug resistance and numerous side-effects limit its therapeutic use (Giaccone 2000; Frezza et al. 2010). Cisplatin cancer chemotherapy can cause acute vascular events and may be associated with an increased long-term cardiovascular risk, electrocardiographic changes, arrhythmias, myocarditis,

Correspondence to: Vladimir Jakovljevic, Institute of Physiology, Faculty of Medical Sciences, University of Kragujevac, Svetozara Markovica 69, 34000 Kragujevac, Serbia

E-mail: drvladakgbg@yahoo.com cardiomyopathy and congestive heart failure (Pai and Nahata 2000; Yeh et al. 2004; Herrmann et al. 2016). The degree of heart injury in humans during cisplatin chemotherapy highly depends on the administered dose (Demkow et al. 2013; Higgins et al. 2015). The mechanism of cisplatin's action on cancer cells is relatively well-known (damaging DNA, inhibiting DNA synthesis and mitosis, and inducing apoptotic cell death), whilst the mechanisms of cisplatininduced cardiotoxicity are still not clear (El-Awady et al. 2011; Dasari and Tchounwou 2014). Several experimental and clinical studies suggested that the cardiotoxicity can be direct consequence of a cisplatin-induced increase in the production of reactive oxidative species (ROS) (Al-Majed et al. 2006; Ferroni et al. 2011). To reduce the systemic toxicity of cisplatin, a thousand of platinum complexes and cisplatin 
<smiles>Cl[PH]1(Cl)NCCN1</smiles>

([Pt(en) $\left.\left.\mathrm{Cl}_{2}\right]\right)$<smiles>N[PH](N)(Cl)Cl</smiles>

CDDP<smiles>Cl[PH]1(Cl)NC2CCCCC2N1</smiles>

$\left(\left[\mathrm{Pt}(\mathrm{dach}) \mathrm{Cl}_{2}\right]\right)$

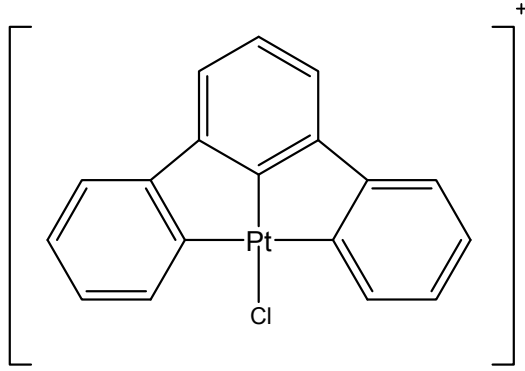

([Pt(terpy)Cl]Cl)
Figure 1. Structures of the examined complexes

analogues have been synthesized and evaluated (Medici et al. 2015). The cisplatin analogues differ in terms of their structures, chemical reactivity, solubility, pharmacokinetics and toxicity (Dasari and Tchounwou 2014). Clinical studies have shown that carboplatin and oxaliplatin had a lower potential to induce systemic toxicity (neurotoxicity, nephrotoxicity, gastrointestinal and metabolic toxicity) (Ozols et al. 2003; Kolomeyevskaya et al. 2015). Therefore, in the present study, we examined and compared the effects of cisplatin (reference compound) and $\mathrm{Pt}(\mathrm{II})$ analogues containing ethylenediamine (en), 1,2-diaminocyclohexane (dach) and 2,2':6,2"'-terpyridine (terpy) as a carrier ligand on cardiac function and coronary flow in the isolated and perfused rat heart (Figure 1) (Connors et al. 1972; Cleare et al. 1978; Kidani et al. 1978; Ahmadi et al. 2006).

The aim of this experimental study was to determine whether structural changes in the complexes (same valence state, different carrier ligand and same leaving ligand-chloride) can modify the cardiotoxic effects in comparison to cisplatin.

\section{Material and Methods}

\section{Isolated rat heart preparation}

The hearts were excised from male Wistar albino rats that were aged between ten and twelve weeks (body mass 200-220 g) and were kept in cages (4 animals/cage: $55 \mathrm{~cm} \mathrm{~L} \times 40 \mathrm{~cm} \mathrm{~W} \times$ $20 \mathrm{~cm} \mathrm{H}$ ) with a day/night cycle (12:12). After short-term anaesthesia with ketamine $(10 \mathrm{mg} / \mathrm{kg})$ and xylazine $(5 \mathrm{mg} / \mathrm{kg})$, the animals were euthanized via cervical dislocation (Schedule 1 of the Animals/Scientific Procedures, Act 1986, UK). Following an urgent thoracotomy and a rapid cardiac arrest by superfusion with ice-cold isotonic saline, the hearts were promptly excised and attached to the Langendorff apparatus via aortic cannulation, and then they were retrogradely perfused under a constant perfusion pressure of $70 \mathrm{~cm} \mathrm{H}_{2} \mathrm{O}$ with Krebs-Henseleit solution. The composition of Krebs-Henseleit solution was as follows (in mmol/l): $\mathrm{NaCl} 118, \mathrm{KCl} 4.7, \mathrm{CaCl} 2$ $\times 2 \mathrm{H}_{2} \mathrm{O} 2.5, \mathrm{MgSO} 4 \times 7 \mathrm{H}_{2} \mathrm{O} 1.7, \mathrm{NaHCO}_{3} 25, \mathrm{KH}_{2} \mathrm{PO}_{4} 1.2$, glucose 11 , pyruvate 2, equilibrated with $95 \% \mathrm{O}_{2}$ plus $5 \% \mathrm{CO}_{2}$, and warmed to $37^{\circ} \mathrm{C}$ ( $\mathrm{pH} 7.4$ ). Immediately after the establishment of automatic operation, a sensor (transducer BS4 73-0184, Experimetria LTD, Budapest, Hungary) was placed into the left ventricle through an incision in the left atrium adjacent to the severed mitral valve to register the pressures.

\section{Experimental groups}

The hearts were divided into four main experimental groups and one control group: 1. Control, perfusion with KrebsHenseleit solution; 2. CDDP, perfusion with cisplatin; 3. $\mathrm{Pt}(\mathrm{en}) \mathrm{Cl}_{2}$, perfusion with dichloro-(ethylenediamine) platinum(II)]); 4. Pt(dach) $\mathrm{Cl}_{2}$, perfusion with dichloro-(1,2diaminocyclohexane)platinum(II) ([]); 5. Pt(terpy)Cl]Cl, perfusion with chloro-(2,2':6',2"-terpyridine)platinum(II) chloride dihydrate; $n=36$ rats per experimental group.

All experimental groups were divided into three subgroups in accordance with the applied dose of the Platinum(II) complex: $1^{\text {st }}$ subgroup $10^{-5} \mathrm{~mol} / \mathrm{l}, 2^{\text {nd }}$ subgroup $10^{-6} \mathrm{~mol} / \mathrm{l}$ and $3^{\text {rd }}$ subgroup $10^{-7} \mathrm{~mol} / \mathrm{l}$. It was taken into consideration that a single dose of cisplatin $\left(10^{-6} \mathrm{~mol} / \mathrm{l}\right)$ can cause cardiotoxicity (Wang et al. 2009). We used that dose, one higher dose $\left(10^{-5} \mathrm{~mol} / \mathrm{l}\right)$ and one lower dose to determine whether cardiotoxic effects are dose-dependent.

All tested substances were administered for 30 minutes, which was followed by a washout period of 15 minutes, according to a previously reported protocol (Peric et al. 2012).

All research procedures were carried out in accordance with the European Directive for the welfare of laboratory animals No 86/609/EEC and principles of Good Laboratory Practice (GLP), approved by an Ethical Committee of the Faculty of Medical Sciences, University of Kragujevac, Serbia.

\section{Experimental protocol}

All hearts underwent a stabilization period, and during this period, each of the hearts was subjected to a short-term occlusion (20 s) followed by simultaneous bolus injections of $5 \mathrm{mmol} / \mathrm{l}$ adenosine $(60 \mu \mathrm{l}$ at a flow of $10 \mathrm{ml} / \mathrm{min}$ to elicit maximal coronary flow) to test the coronary vascular reactivity. Coronary flow (CF), as a parameter of coronary circulation, was measured flowmetrically. In all experimental 


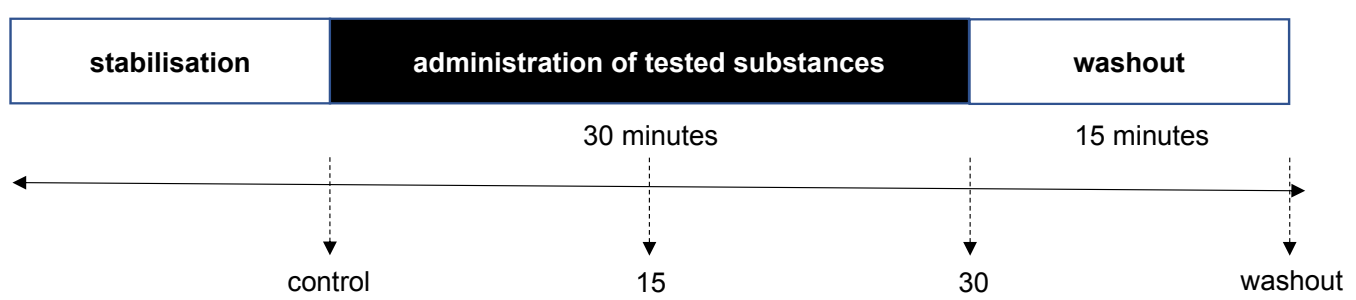

Figure 2. Experimental protocol on an isolated rat heart.

groups, the following parameters of heart function were continuously recorded: maximum rate of left ventricular pressure development $\left(\mathrm{LV}(\mathrm{dP} / \mathrm{dt})_{\max }\right)$, minimum rate of left ventricular pressure development $\left(\mathrm{LV}(\mathrm{dP} / \mathrm{dt})_{\min }\right)$, left ventricular systolic pressure (LVSP), left ventricular diastolic pressure (LVDP), and heart rate (HR).

The end of the stabilization period and the beginning of the experimental period was when the CF was stabilized (three successive measurements of the same value). At the beginning of the experiment, all cardiodynamic parameters and CF were measured, and those values were marked as the baseline value. Then, the perfusion was started with an appropriate concentration of each compound, depending on the group.

We also measured all cardiodynamic parameters and CF at the last minute of the substance application (effect) and at the last minute of the washout period (washout) (Figure 2).

\section{Tissue processing for light microscopy}

Tissue was prepared for morphological analysis as described in previous publications. After immersion fixation in $4 \%$ neutrally buffered formaldehyde, the tissue was dehydrated and embedded in paraffin and then sectioned in 4-micrometre thick sections and stained with Masson's trichrome.

Morphological changes were described and graded, and the tissue damage score was obtained according to previously established and modified grading systems (Trajkovic et al. 2007). The pathologist who performed the analysis was blinded to the data from the experimental groups.

\section{Substances (chemicals)}

All chemicals and cisplatin were obtained from SigmaAldrich GmbH, Germany, and were of p.a. grade quality.

Platinum(II) complexes have been synthesized according to described procedures (Annibale et al. 1995; Galanski and Keppler 1995).

\section{Statistical analysis}

All values are expressed as the mean \pm SD. A Wilcoxon signed-rank test (for the difference between related samples) was used to analyse effects of a substance in the subgroup (baseline $v s$. effect; effect $v s$. washout; baseline $v s$. washout). The Wilcoxon signed-rank test was used in the statistical analysis, and $p$ values less than 0.05 were statistically significant. For the comparison of the complexes' effects amongst the groups, we used an ANOVA, and $p$ values less than 0.05 were statistically significant. For multiple comparisons after the ANOVA, we used a post hoc test (Bonferroni when homogeneity of variance was higher than 0.05 and Dunnett T3 when homogeneity of variance was lower than 0.05 ). The statistical analysis was performed using SPSS 19.0 for Windows.

\section{Results}

\section{The effects of cisplatin administration on cardiodynamic parameters and coronary flow}

The $\mathrm{LV}(\mathrm{dP} / \mathrm{dt})_{\max }$ was significantly decreased only after administration the highest dose of cisplatin when effect and also washout were compared to baseline (Fig. 3A). The administration of all doses of cisplatin induced a statistically significant decrease in $\mathrm{LV}(\mathrm{dP} / \mathrm{dt})_{\min }$, when washout was compared to baseline (Fig. 3B, 4B, 5B), while middle and the lowest dose also induced decrease when effect was compared to baseline (Fig. 4B, 5B). All doses of cisplatin induced decrease of LVSP, when washout was compared to baseline (Fig. 3C, 4C, 5C). In addition, the middle and the highest doses induced decrease of LVSP when effect was compared to baseline (Fig. 4C, 3C). Also after administration of the highest dose, decrease of LVSP was observed when effect was compared with washout (Fig. 3C). The administration of the highest dose of cisplatin induced decrease of HR when effect and also washout were compared to baseline (Fig. 3E). On the other hand, middle dose induced decrease when washout was compared to baseline (Fig. 4E), while the lowest dose induced decrease of HR when effect was compared to baseline Fig. 5E). The CF was significantly decreased only after administration the highest dose of cisplatin, when washout was compared to baseline (Fig. 3F). All the observed changes in the cardiodynamic parameters were irreversible, except for a decrease HR after administration of the lowest dose. The LVDP was not significantly changed after the administration of any dose (Fig. 3D, 4D, 5D). 
The effect of $\left[\mathrm{Pt}(\mathrm{en}) \mathrm{Cl}_{2}\right]$ administration on cardiodynamic parameters and coronary flow

The administration of the highest and the lowest doses of $\left[\mathrm{Pt}(\mathrm{en}) \mathrm{Cl}_{2}\right]$ induced a statistically significant decrease in $\mathrm{LV}(\mathrm{dP} / \mathrm{dt})_{\min }$ when washout was compared to baseline (Fig. 3B, 5B). The administration of the highest and the lowest doses of $\left[\mathrm{Pt}(\mathrm{en}) \mathrm{Cl}_{2}\right]$ induced a statistically significant decrease of LVSP when washout was compared to baseline (Fig. 3C, 5C). LVSP was also decreased when effect was compared to baseline, after administration of the highest dose (Fig. 3C). On the other hand, the administration of the highest and middle doses of $\left[\mathrm{Pt}(\mathrm{en}) \mathrm{Cl}_{2}\right]$ induced a significant decrease of $\mathrm{HR}$, when effect was compared to baseline (Fig. 3E, 4E), while the middle dose also induced decrease when washout was compared to baseline (Fig. $4 \mathrm{E})$. All observed changes in cardiodynamic parameters were irreversible. The values of $\mathrm{LV}(\mathrm{dP} / \mathrm{dt})_{\max }$ (Fig. 3A, 4A, 5A), LVDP (Fig. 3D, 4D, 5D) and CF (Fig. 3F, 4F, 5F) were not statistically significantly changed during $[\mathrm{Pt}(\mathrm{en})$ $\mathrm{Cl}_{2}$ ] administration.

\section{The effect of [Pt(dach) $\left.\mathrm{Cl}_{2}\right]$ administration on cardiodynamic parameters and coronary flow}

The administration of all doses of $\left[\mathrm{Pt}(\mathrm{dach}) \mathrm{Cl}_{2}\right]$ induced a significant decrease in $\mathrm{LV}(\mathrm{dP} / \mathrm{dt})_{\min }$ when washout was compared to baseline (Fig. 3B, 4B, 5B). The administration


Figure 3. The effects of the highest dose $\left(10^{-5} \mathrm{~mol} / \mathrm{l}\right)$ of platinum(II) complexes on cardiodynamic parameters and coronary flow. The results are presented as the mean $\pm \mathrm{SD}(n=12)$. The differences within the same group induced by complex: ${ }^{*} p<0.05$ baseline $v s$. washout. The differences between the groups induced by different complexes are labelled with letters: ${ }^{\mathrm{a}} p<0.05 v s$. $[\mathrm{Pt}(\mathrm{terpy}) \mathrm{Cl}] \mathrm{Cl} ;{ }^{\mathrm{c}} p<0.05$ $v s$. cisplatin at the respective time point of the experiment. 
of middle and the lowest doses induced decrease of LVSP when washout was compared to baseline (Fig. 4C, 5C), while the lowest dose also induced decrease when effect was compared to baseline (Fig. 5C). The administration of the highest and middle doses of $\left[\mathrm{Pt}(\mathrm{dach}) \mathrm{Cl}_{2}\right]$ induced a significant decrease in HR when effect and also washout were compared to baseline (Fig. 3E, 4E). The administration of the highest dose of $\left[\mathrm{Pt}(\mathrm{dach}) \mathrm{Cl}_{2}\right]$ induced increase of CF when effect was compared to baseline (Fig. 3F). All observed changes in cardiodynamic parameters were irreversible. LVDP (Fig. 3D, 4D, 5D) and $\mathrm{LV}(\mathrm{dP} / \mathrm{dt})_{\max }$ (Fig. 3A, 4A, 5A) were not significantly changed after the administration of any dose.
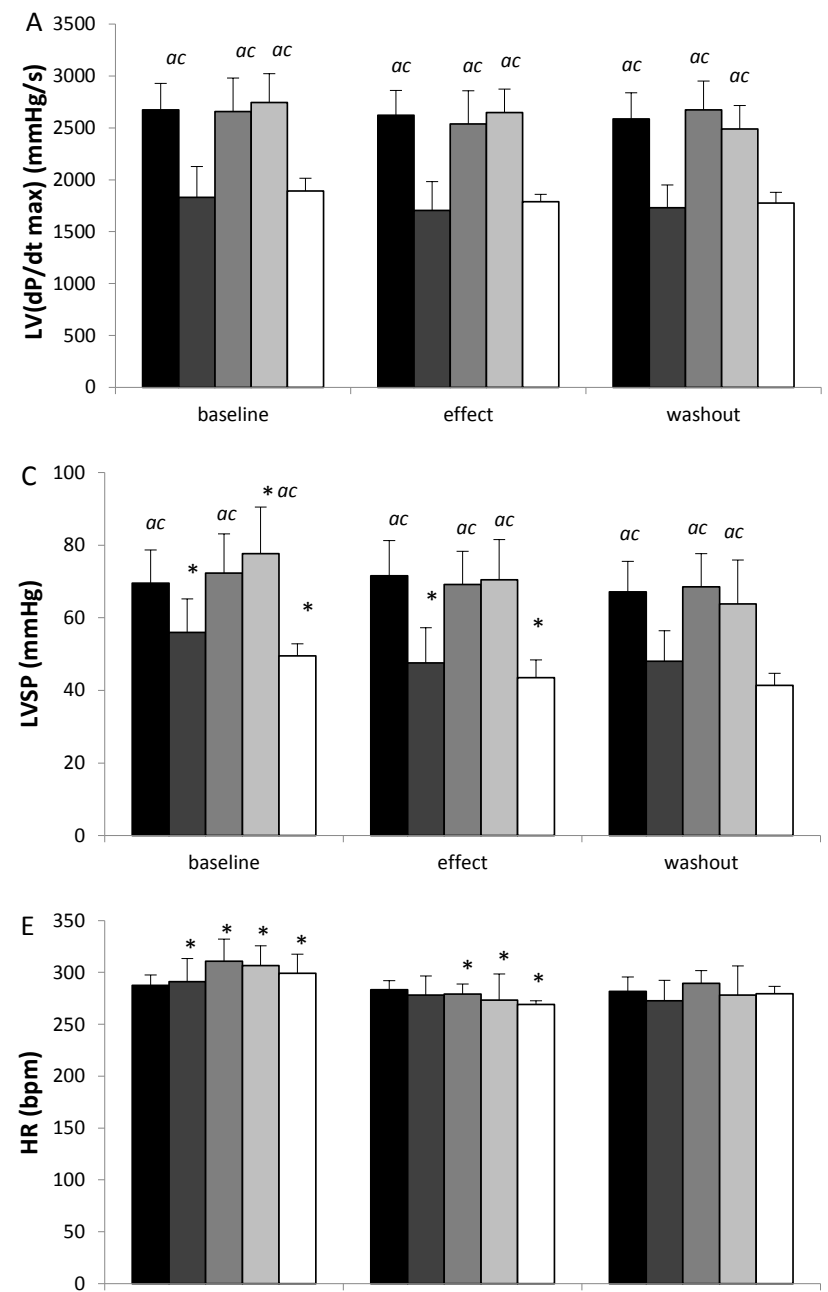

baseline

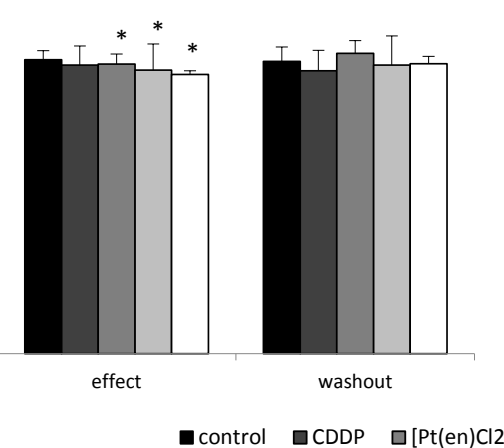

The effect of [Pt(terpy)Cl]Cl administration on cardiodynamic parameters and coronary flow

$\mathrm{LV}(\mathrm{dP} / \mathrm{dt})_{\max }$ was significantly decreased only after the administration of the highest dose of [Pt(terpy) $\mathrm{Cl}] \mathrm{Cl}$ when all points of interest were compared (Fig. 3A). The administration of $[\mathrm{Pt}($ terpy $) \mathrm{Cl}] \mathrm{Cl}$ in all doses induced a statistically significant decrease of $\mathrm{LV}(\mathrm{dP} / \mathrm{dt})_{\min }$ when effect was compared to baseline (Fig. 3B, Fig. 4B, Fig. 5B). While the highest and middle doses induced decrease of $\operatorname{LV}(\mathrm{dP} / \mathrm{dt})$ min when washout was compared to baseline. All doses of $[\mathrm{Pt}$ (terpy) $\mathrm{Cl}] \mathrm{Cl}$ induced decrease of LVSP when washout was compared to baseline (Fig. 3C, 4C, 5C). In addition,
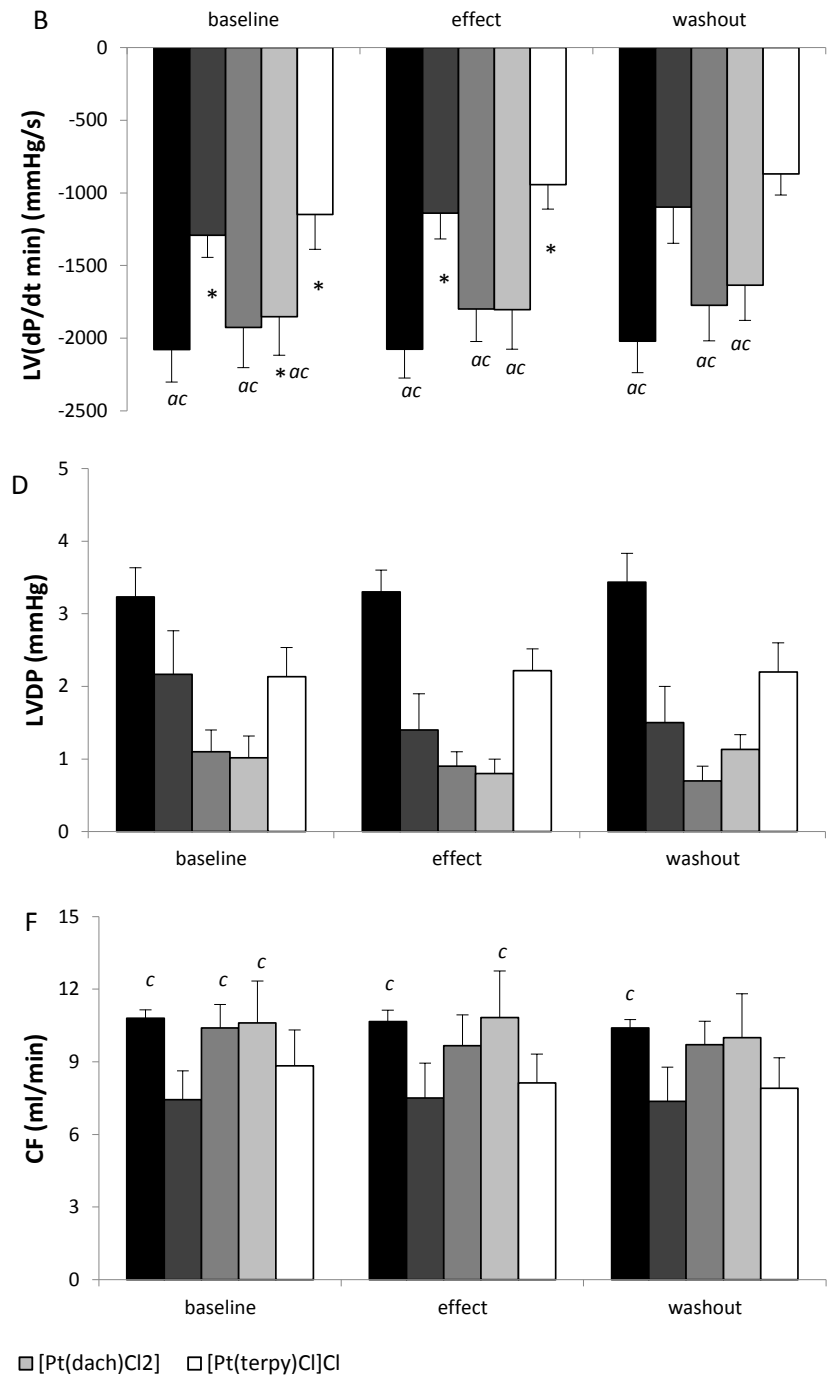

Figure 4. The effects of middle dose $\left(10^{-6} \mathrm{~mol} / \mathrm{l}\right)$ of platinum(II) complexes on cardiodynamic parameters and coronary flow. The results are presented as the mean $\pm \mathrm{SD}(n=12)$. The differences within the same group induced by complex: ${ }^{\star} p<0.05$ baseline $v s$. washout. The differences between the groups induced by different complexes are labelled with letters: ${ }^{\mathrm{a}} p<0.05 v s$. [Pt(terpy)Cl] $\mathrm{Cl} ;{ }^{c} p<0.05 v s$. cisplatin at the respective time point of the experiment. 
the middle and the highest doses induced decrease of LVSP when effect was compared to baseline (Fig. 4C, 3C). Also after administration of the highest dose, decrease of LVSP was observed when effect was compared with washout (Fig. 3C). HR was significantly decreased after the highest and middle dose when washout and also effect were compared to baseline (Fig. 3E, 4E), while the highest dose also induced decrease when washout was compared to effect (Fig. 3E). CF was significantly decreased only after the administration of the highest dose of $[\mathrm{Pt}($ terpy $) \mathrm{Cl}] \mathrm{Cl}$ when all points of interest were compared (Fig. 3F). All the observed changes in cardiodynamic parameters were irreversible. The LVDP was not significantly changed after the administration of any dose (Fig. 3D, 4D, 5D).
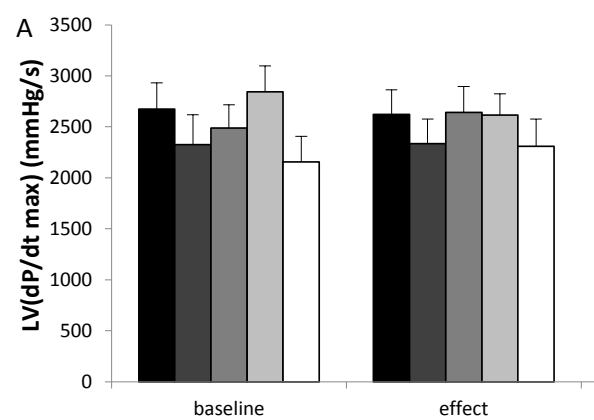

effect

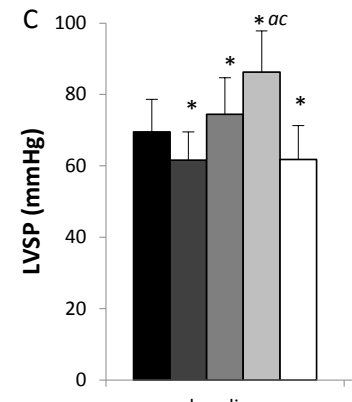

baseline

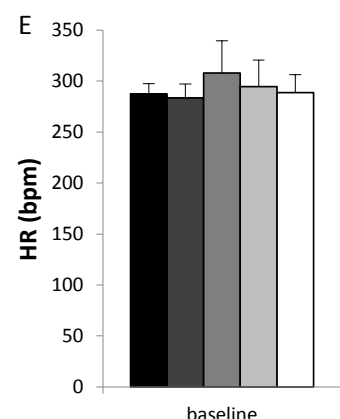

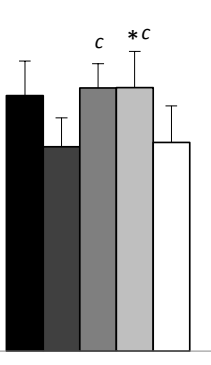

effect

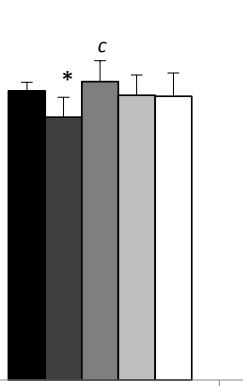

effect

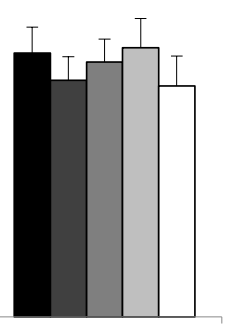

washout

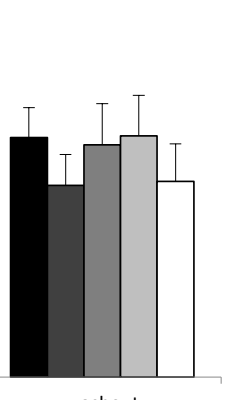

washout

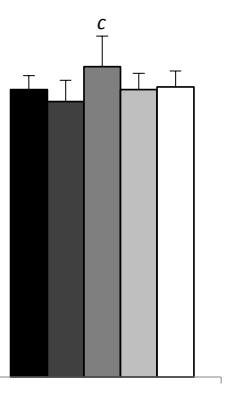

washout

- control $\square$ CDDP $\square[\mathrm{Pt}(\mathrm{en}) \mathrm{Cl} 2]$

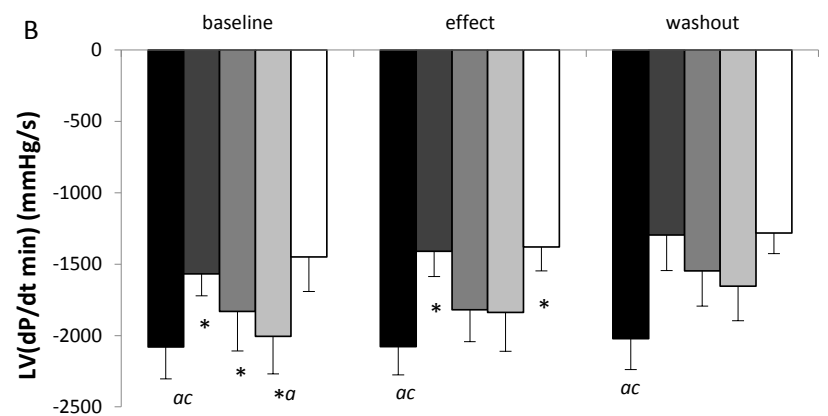

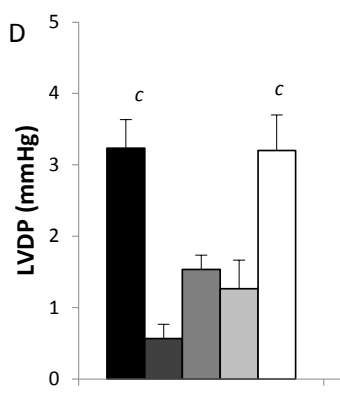

baseline

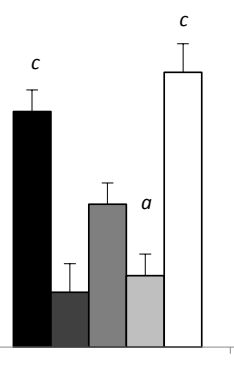

effect

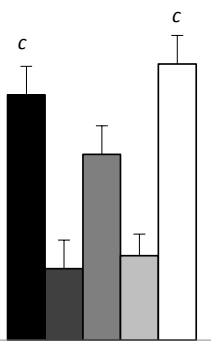

washout

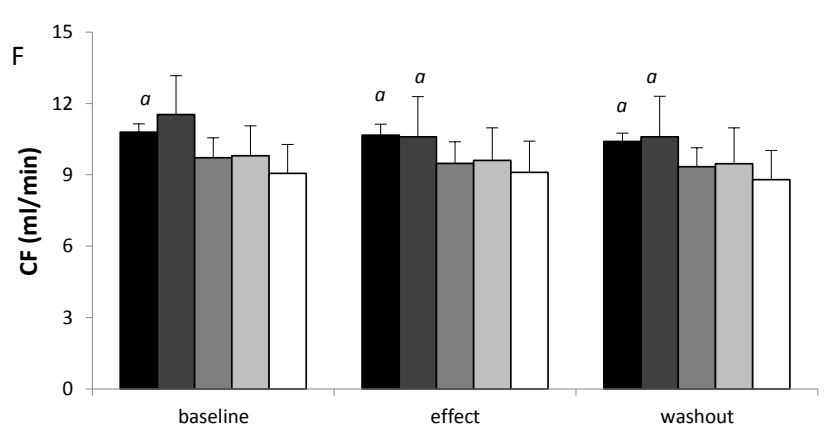

Figure 5. The effects of the lowest dose $\left(10^{-7} \mathrm{~mol} / \mathrm{l}\right)$ of platinum(II) complexes on cardiodynamic parameters and coronary flow. The results are presented as the mean $\pm \mathrm{SD}(n=12)$. The differences within the same group induced by complex: ${ }^{\star} p<0.05$ baseline $v s$. washout. The differences between the groups induced by different complexes are labelled with letters: ${ }^{\mathrm{a}} p<0.05 v$ s. $[\mathrm{Pt}(\mathrm{terpy}) \mathrm{Cl}] \mathrm{Cl} ;{ }^{\mathrm{c}} p<0.05$ $v s$. cisplatin at the respective time point of the experiment. 
Henseleit solution in effect and washout (Fig. 3A, 3B, 3C, 3F). Additionally, the values of LVSP after the administration of the Krebs-Henseleit solution were higher compared to values of LVSP after the administration of all complexes in effect and washout (Fig. 3C). Administration of CDDP induced higher decrease of CF compared to control, $\left[\mathrm{Pt}(\mathrm{en}) \mathrm{Cl}_{2}\right]$ and $\left[\mathrm{Pt}(\mathrm{dach}) \mathrm{Cl}_{2}\right]$ in effect and washout (Fig. 3F). The highest doses of CDDP and $[\mathrm{Pt}($ terpy $) \mathrm{Cl}] \mathrm{Cl}$ induced statistically significant decrease of HR compared to Krebs-Henseleit solution in effect (Fig. 3E). [Pt(terpy)Cl]Cl induced statistically significant decrease of HR compared to other complexes and control in washout point (Fig. 3E). The baseline values of LVDP amongst the [Pt(terpy)Cl]Cl group and the [Pt(en) $\left.\mathrm{Cl}_{2}\right]$ and $\left[\mathrm{Pt}(\right.$ dach $) \mathrm{Cl}_{2}$ ] groups were significantly different, so the effects of those complexes on LVDP cannot be compared to each other (Fig. 3D). There were no differences between the $\left[\mathrm{Pt}(\mathrm{en}) \mathrm{Cl}_{2}\right]$ and $\left[\mathrm{Pt}(\mathrm{dach}) \mathrm{Cl}_{2}\right]$ groups regarding any of the examined cardiodynamic parameters as well as in coronary flow.

The comparison of the effects of middle doses of applied complexes on cardiodynamic parameters and CF

The baseline of the $\operatorname{LV}(\mathrm{dP} / \mathrm{dt})_{\max }, \mathrm{LV}(\mathrm{dP} / \mathrm{dt})_{\min }$ and LVSP in $[\mathrm{Pt}($ terpy $) \mathrm{Cl}] \mathrm{Cl}$ and cisplatin groups were statistically significant different compared to the $\left[\mathrm{Pt}(\mathrm{en}) \mathrm{Cl}_{2}\right],[\mathrm{Pt}(\mathrm{dach})$ $\mathrm{Cl}_{2}$ ] and control groups, so we could not compare the effects of those complexes on $\mathrm{LV}(\mathrm{dP} / \mathrm{dt})_{\max }$ (Fig. 4A), LV(dP/dt) min (Fig. 4B) and LVSP (Fig. 4C). In addition, the baseline of $\mathrm{CF}$ in cisplatin group was different in comparison with $\left[\mathrm{Pt}(\mathrm{en}) \mathrm{Cl}_{2}\right],\left[\mathrm{Pt}(\mathrm{dach}) \mathrm{Cl}_{2}\right]$ and control groups, so the different effects of those complexes on CF (Fig. 4F) cannot be compared to each other. There were no statistically significant differences in HR between the groups (Fig. 4E).

The comparison of the effects of the lowest doses of applied complexes on cardiodynamic parameters and CF

Cisplatin, at the lowest dose $\left(10^{-7} \mathrm{M}\right)$, induced a statistically significant decrease in LVSP (Fig. 5C) and HR (Fig. 5E) in effect compared to $\left[\mathrm{Pt}(\mathrm{en}) \mathrm{Cl}_{2}\right]$. As there were significant differences in the basaline values of the other parameters investigated, the effects of individual complexes were not compared to each other.

\section{The effects of Platinum(II) complexes on histopathology of isolated rat heart}

The preserved structure of the heart was confirmed by histological analysis in all groups. Cardiomyocytes were of regular morphology, with the proper arrangement of myofibrils and one or two centrally located oval euchromatic nuclei. The morphology of the blood vessels was also preserved. In some samples, focally degenerative changes of cardiomyocytes and vascular changes were observed, which were marked as mild to medium (Table 1). Mild

Table 1. The effects of platinum(II) complexes perfusion on heart tissue of isolated rat heart - tissue damage score for degenerative and vascular changes

\begin{tabular}{lccc}
\hline Group & $\begin{array}{c}\text { Tissue damage } \\
\text { score (grade) }\end{array}$ & $\begin{array}{c}\text { Vascular damage } \\
\text { score (grade) }\end{array}$ & $\begin{array}{c}\text { Overall tissue } \\
\text { damage score }\end{array}$ \\
\hline $\mathrm{CDDP}\left(10^{-5} \mathrm{~mol} / \mathrm{l}\right)$ & 1 & 1 & 2 \\
$\mathrm{CDDP}\left(10^{-6} \mathrm{~mol} / \mathrm{l}\right)$ & 1 & 1 & 2 \\
{$\left[\mathrm{Pt}(\mathrm{en}) \mathrm{Cl}_{2}\right]\left(10^{-5} \mathrm{~mol} / \mathrm{l}\right)$} & 1 & 3 & 4 \\
{$\left[\mathrm{Pt}(\mathrm{en}) \mathrm{Cl}_{2}\right]\left(10^{-6} \mathrm{~mol} / \mathrm{l}\right)$} & 1 & 3 & 4 \\
{$\left[\mathrm{Pt}(\right.$ dach $\left.) \mathrm{Cl}_{2}\right]\left(10^{-5} \mathrm{~mol} / \mathrm{l}\right)$} & 1 & 3 & 4 \\
{$\left[\mathrm{Pt}(\right.$ dach $\left.) \mathrm{Cl}_{2}\right]\left(10^{-6} \mathrm{~mol} / \mathrm{l}\right)$} & 1 & 0 & 1 \\
$[\mathrm{Pt}$ terpy $) \mathrm{Cl}] \mathrm{Cl}\left(10^{-5} \mathrm{~mol} / \mathrm{l}\right)$ & 1 & 2 & 3 \\
{$[\mathrm{Pt}$ terpy)Cl $] \mathrm{Cl}\left(10^{-6} \mathrm{~mol} / \mathrm{l}\right)$} & 1 & 2 & 3 \\
Control & 0 & 0 & 0 \\
\hline
\end{tabular}

Tissue damage score (grade): 0 , Normal finding; 1, single cells with small cytoplasmatic vacuoles, slightly enlarged, and with normal /pyknotic nuclei; $2,>50 \%$ cells with mild vacuolization of cytoplasm and nucleoplasm; 3 , all cells with pronounced vacuolization of cytoplasm and nucleoplasm, and pycnotic nuclei; 4, pronounced plasmolysis and caryolysis and diffuse infiltration of polymorphonuclear cells (PMNCs) that surround and phagocyte dead cells. Vascular damage score (grade): 0 , normal findings; 1 , mild dilatation of small blood vessels with no changes in continuation of their walls, but with changes of endothelium; 2 , increased blood volume with stasis and hyaline microthrombi; 3 , transmural rupture of small number (up to 50\%) of blood vessels (mild focal haemorrhagiae diapedesis) associated with no accumulation of PMNCs; 4, complete loss of the basal membrane and endothelial cells of large number of blood vessels $(>50 \%)$ and high intensity haemorrhagiae diapedesis. Overall tissue damage score is presented as the sum of tissue damage score and vascular damage score. 
interstitial and intracellular oedemas along with vacuolization were observed in all groups (Fig. 6A-H), particularly in $\left[\mathrm{Pt}(\right.$ dach $\left.) \mathrm{Cl}_{2}\right]\left(10^{-5} \mathrm{~mol} / \mathrm{l}\right)$ (Fig. 6C). Discrete derangement of myofibrils was noted in $\left[\mathrm{Pt}(\mathrm{en}) \mathrm{Cl}_{2}\right]\left(10^{-5} \mathrm{~mol} / \mathrm{l}\right)$ (Fig. $6 \mathrm{~A})$, with a partial enlargement of intermyofibrillar spaces on one side of the same cardiomyocyte and a gathering of myofibrils on the other part of sarcoplasm. In almost all groups, "contraction band" necrosis phenomena were clearly visible (Fig. 6A, C-H). Vacuolization and intracellular oedema were followed with karyopiknosis as single cell phenomena in all groups (Fig. 6A-H). Extravasations of red blood cells (haemorrhagiae diapedesis) were most readily observed in the $\left[\mathrm{Pt}(\mathrm{en}) \mathrm{Cl}_{2}\right]\left(10^{-5} \mathrm{~mol} / \mathrm{l}\right),[\mathrm{Pt}(\mathrm{en})$ $\mathrm{Cl}_{2}$ ] $\left(10^{-6} \mathrm{~mol} / \mathrm{l}\right)$ and $\left[\mathrm{Pt}(\mathrm{dach}) \mathrm{Cl}_{2}\right]\left(10^{-5} \mathrm{~mol} / \mathrm{l}\right)$ groups (Fig. 6A-C). Stasis of fluids and the deposition of fibrine in a form of hyaline microthrombi was encountered only in the $[\mathrm{Pt}($ terpy $) \mathrm{Cl}] \mathrm{Cl}\left(10^{-5} \mathrm{~mol} / \mathrm{l}\right)$ and $[\mathrm{Pt}($ terpy $) \mathrm{Cl}] \mathrm{Cl}\left(10^{-6}\right.$ mol/l) groups (Fig. 6G, H).

\section{Discussion}

Cisplatin-induced cardiotoxicity, in humans, may occur as an early or late complication during antitumour therapy (Meinardi et al. 2000). In an experimental model of an isolated mouse heart, it has been shown that cisplatin can induce the depression of myocardial contractile function (Ma et al. 2010).

The results of human trials confirmed that administration of $5 \mathrm{mg} / \mathrm{kg}$ of cisplatin in total, expressed as weekly dose, resulted in total platinum plasma levels in the range of 1.60-2.60 $\mu \mathrm{g} / \mathrm{l}$ (Sunderman et al. 1990). On the other
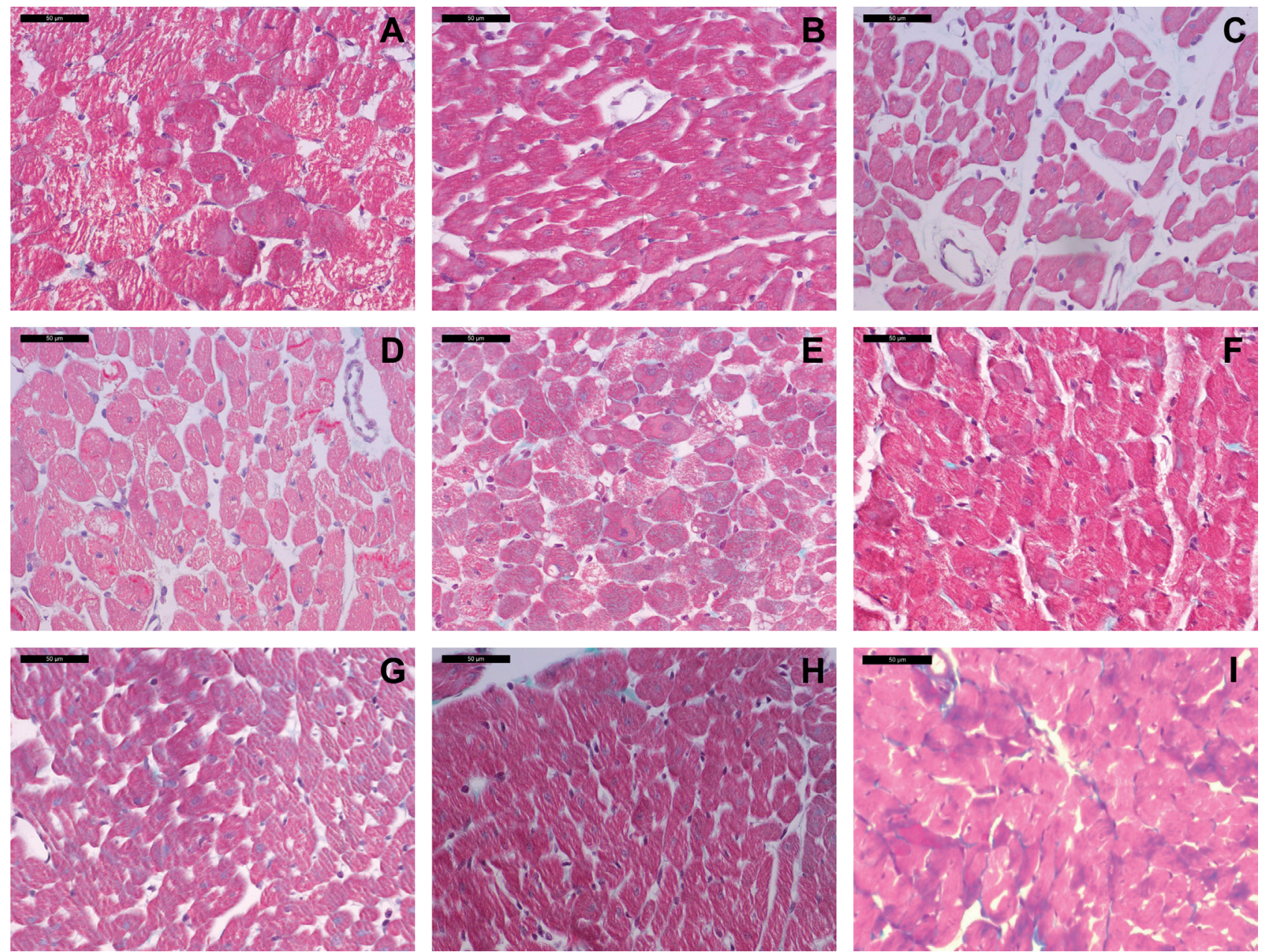

Figure 6. Microscopic evidence of heart toxicity after perfusion of platinum(II) complexes through an isolated rat heart (Masson's trichrome). The effects of $\left.\left[\mathrm{Pt}(\mathrm{en}) \mathrm{Cl}_{2}\right](\mathbf{A}, \mathbf{B}), \mathrm{Pt}(\mathrm{dach}) \mathrm{Cl}_{2}\right](\mathbf{C}, \mathbf{D}) \mathrm{CDDP}(\mathbf{E}, \mathbf{F}),[\mathrm{Pt}($ terpy $) \mathrm{Cl}] \mathrm{Cl}(\mathbf{G}, \mathbf{H})$ perfusion on heart tissue. I. The effects of Krebs-Henseleit solution perfusion on heart tissue. Magnification $\times 400$ (bar $=50 \mu \mathrm{m}$ ). Arrows represented focally observed degenerative changes of cardiomyocytes and vascular changes. 
hand, the same concentration of cisplatin, administered as a single dose, in Wistar Albino rats resulted in the mean plasma concentration of total platinum content between 1 and $10 \mu \mathrm{g} / \mathrm{l}$ (Uchino et al. 2005) and tissue levels of cisplatin between 1-40 $\mu \mathrm{g} / \mathrm{l}$ (Valentovic et al. 1991). Taking into the consideration that a single dose of cisplatin $(7 \mathrm{mg} / \mathrm{kg})$ administered intraperitoneally can induce cardiotoxicity (Wang et al. 2009); we calculated that the appropriate dose for an isolated rat heart is $10^{-6} \mathrm{~mol} / \mathrm{l}$. Thus, we examined the effects of this dose, along with one higher and one lower dose.

In the presented study, cisplatin and $[\mathrm{Pt}($ terpy $) \mathrm{Cl}] \mathrm{Cl}$ showed the greatest impact on myocardial function at the highest (Fig. 3A,B) and middle doses (Fig. 4A,B), compared to other complexes. Nevertheless, comparing the effects of these two complexes at higher dose $[\mathrm{Pt}$ (terpy) $\mathrm{Cl}] \mathrm{Cl}$ had the most depressive effect (Fig. 3A,B). The highest dose induced a decrease in $\mathrm{LV}(\mathrm{dP} / \mathrm{dt})_{\min }$ in all experimental groups (Fig. $3 \mathrm{~B})$. Our results for the effects of CDDP on contractility agree with a previous study (Ma et al. 2010). Ma et al. showed that a one-week treatment with cisplatin $(10 \mathrm{mg} / \mathrm{kg}$ per day i.v.) reduced left ventricular developed pressure in isolated C57BL/6 mice hearts retrogradely perfused with KrebsHenseleit buffer. They demonstrated that cisplatin-induced cardiac dysfunction was associated with mitochondrial membrane depolarization. The changes of contractility, observed in our study, induced by perfusion with the complexes were completely irreversible. The values of $\mathrm{LV}(\mathrm{dP} / \mathrm{dt}) \max$ and $\mathrm{LV}(\mathrm{dP} / \mathrm{dt})$ min were lower after the washout period and related to values recorded at the end of perfusion of applied substances (Fig. 3A, 3B, 4A, 4B, 5A, 5B).

The values of LVSP were affected by perfusion of isolated rat heart with all complexes, but to a different extent. Cisplatin and $[\mathrm{Pt}($ terpy $) \mathrm{Cl}] \mathrm{Cl}$ induced decrease of LVSP regardless of the applied dose. On the other hand $\left[\mathrm{Pt}(\mathrm{dach}) \mathrm{Cl}_{2}\right]$ induced decrease of LVSP at middle and the lowest doses, and [Pt(en) $\mathrm{Cl}_{2}$ ] induced decrease of LVSP at the highest and the lowest doses. All changes were completely irreversible. Our results agree with the findings that cisplatin use can decrease the mean arterial blood pressure (Ma et al. 2010; El-Sawalhi et al. 2014). El-Sawalhi et al. demonstrated that a single dose of cisplatin $(7 \mathrm{mg} / \mathrm{kg}$ i.p.) in Wistar male rats can induce a significant decrease in mean arterial blood pressure and heart rate. These effects are observed five days after cisplatin administration.

All complexes had a great impact on HR at the highest (Fig. 3E) and the middle (Fig. 4E) doses, and only cisplatin induced a decrease in HR at the lowest dose $v s$. baseline (Fig. $5 \mathrm{E})$. The largest reduction in HR was induced by cisplatin and by [ $\mathrm{Pt}($ terpy) $\mathrm{Cl}] \mathrm{Cl}$ compared to control group (Fig. 3E). This result agrees with previously published data (Wang et al. 2009; El-Sawalhi et al. 2014). Wang et al. using the same model as Sawalhi et al, showed that cisplatin induced a significant decrease of HR and LVSP using tail-cuff plethysmographic methods.

Cisplatin-induced bradycardia usually occurs at the very beginning of cisplatin chemotherapy (Altundağ et al. 2001; Dieckmann et al. 2011; Kounis et al. 2016; Kucharz et al. 2016). In our experiment, we found similar trend for HR. The mechanism of cisplatin-induced arrhythmia is unknown, and it remains to be examined.

Our histopathology results, for all experimental groups, have shown focal irregularly arranged myofibrils with a hypercontraction of sarcomeres. Their sarcomeres appeared shorter and occasionally with contraction band necrosis, mostly seen at higher doses (Table 1 and Fig. 6). This phenomenon could potentially be explained by an uncontrolled influx of $\mathrm{Ca}^{2+}$ ions, leading to a dissociated contraction of the cardiomyocytes with hypercontraction of the sarcomeres and contraction band necrosis. Accordingly, this could be one reason for the depressive effect on the myocardium.

The highest dose of cisplatin and $[\mathrm{Pt}($ terpy $) \mathrm{Cl}] \mathrm{Cl}$ induced decrease in CF, which was significant in comparison with effects of the remaining two complexes and the KrebsHenseleit solution (Fig. 3F). The highest dose of $[\mathrm{Pt}(\mathrm{dach})$ $\mathrm{Cl}_{2}$ ] induced an increase in CF (Fig. 3F) vs. baseline. Other doses of complexes did not induce a significant reduction in CF. The strongest reduction in CF was with $[\mathrm{Pt}$ (terpy) $\mathrm{Cl}] \mathrm{Cl}$ perfusion $(65 \%)$. The dramatic reduction in $\mathrm{CF}$ in the group treated with $[\mathrm{Pt}($ terpy $) \mathrm{Cl}] \mathrm{Cl}$ at the higher dose could be potentially explained by the formation of hyaline microthrombi that was only observed in this group (Table 1 and Fig. 6G). The formation of hyaline microthrombi is an indicator of disrupted microcirculation and haemostasis (Oehmichen et al. 1986).

Hydrolysis reactions of platinum(II) complexes (platinum ammine halides) depend on a carrier ligand and its voluminosity (Bugarcic et al. 2012; Johnstone et al. 2016). According to the values of the reaction rate constants, it can be concluded that our examined complexes are good nucleophiles. The reactivity of complexes depends on the voluminosity of the carrier ligands. $\left[\mathrm{Pt}(\mathrm{dach}) \mathrm{Cl}_{2}\right]$ has the most voluminous ligand (amongst $\left[\mathrm{Pt}(\mathrm{en}) \mathrm{Cl}_{2}\right],\left[\mathrm{Pt}(\mathrm{dach}) \mathrm{Cl}_{2}\right]$ and $\left[\mathrm{Pt}\left(\mathrm{NH}_{3}\right)\right.$ $\left.\mathrm{Cl}_{2}\right]$ ), and it has the slowest substitution reaction rate. Considering that the dach ligand has a positive inductive effect, platinum in $\left[\mathrm{Pt}(\mathrm{dach}) \mathrm{Cl}_{2}\right]$ becomes less electronegative. On the other hand, $\left[\mathrm{Pt}(\mathrm{en}) \mathrm{Cl}_{2}\right]$ has lower positive inductive effect, so it has faster substitution reaction rate than $[\mathrm{Pt}(\mathrm{dach})$ $\mathrm{Cl}_{2}$ ]. Since CDDP has unsubstituted amino ligands, it has a faster rate of substitution reaction than that of $[\mathrm{Pt}(\mathrm{dach})$ $\left.\mathrm{Cl}_{2}\right]$ and $\left[\mathrm{Pt}(\mathrm{en}) \mathrm{Cl}_{2}\right]$. The lower reactivity caused a reduced nonspecific interaction with endogenous molecules; therefore, it lowers toxicity. The introduction of pyridine rings, which are $\pi$-acceptors, may increase the electrophilicity on the $\mathrm{Pt}$ (II) metal centre due to their electron-withdrawing properties. The addition of these aromatic rings can result 
in increasing reaction rates for nucleophilic substitution reactions in the case of $\left[\mathrm{Pt}(\text { terpy) } \mathrm{Cl}]^{+}\right.$(Hofmann et al. 2003; Bugarcic et al. 2004; Summa et al. 2006). These structural differences could be the explanation for why perfusion with $[\mathrm{Pt}($ terpy $) \mathrm{Cl}] \mathrm{Cl}$ has the strongest myocardial depression related to CDDP, $\left[\mathrm{Pt}(\mathrm{en}) \mathrm{Cl}_{2}\right]$ and $\left[\mathrm{Pt}(\mathrm{dach}) \mathrm{Cl}_{2}\right]$. Our histopathological findings showed that there were no permanent changes during perfusion.

In general, we noted that the deleterious effects on heart function and $\mathrm{CF}$ are more pronounced with $[\mathrm{Pt}($ terpy $) \mathrm{Cl}]$ $\mathrm{Cl}$ compared to the other examined complexes. This finding agrees with the known statement that introducing an aromatic ring in a drug's structure can increase toxicity. The two other complexes had shown a less negative effect on heart function compared to cisplatin. In that sense, these findings can be of interest for a possible synthetic strategy for new platinum-based anticancer agents in terms of their carrier ligand structure, mode of coordination and valence state, which can lead to platinum-based drugs with less cardiotoxic potentials.

Acknowledgements. This work was supported by grant No. 175043 and 175007 of the Ministry of Education, Science and Technological Development of the Republic of Serbia.

\section{References}

Al-Majed AA, Sayed-Ahmed MM, Al-Yahya AA, Aleisa AM, Al-Rejaie SS, Al-Shabanah OA (2006): Propionyl-L-carnitine prevents the progression of cisplatin-induced cardiomyopathy in a carnitine-depleted rat model. Pharmacol. Res. 53, 278-286 https://doi.org/10.1016/j.phrs.2005.12.005

Aller SG, Unger VM (2006) : Projection structure of the human copper transporter CTR1 at 6-A resolution reveals a compact trimer with a novel channel-like architecture. Proc. Natl. Acad. Sci. USA 103, 3627-3632

https://doi.org/10.1073/pnas.0509929103

Altundağ O, Celik I, Kars A (2001): Recurrent asymptomatic bradycardia episodes after cisplatin infusion. Ann. Pharmacother. 35, 641-642 https://doi.org/10.1345/aph.10180

Andrews PA, Mann SC, Huynh HH, Albright KD (1991): Role of the $\mathrm{Na}+, \mathrm{K}(+)$-adenosine triphosphatase in the accumulation of cis-diamminedichloroplatinum(II) in human ovarian carcinoma cells. Cancer. Res. 51, 3677-3681

Annibale G, Brandolisio M, Pitteri B (1995): New routes for the synthesis of chloro(diethylenetriamine) platinum(II) chloride and chloro $\left(2,2^{\prime}: 6^{\prime}, 2^{\prime}\right.$-terpyridine) platinum(II) chloride dihydrate. Polyhedron 14, 451-453 https://doi.org/10.1016/0277-5387(94)00408-7

Bers DM, Barry WH, Despa S (2003): Intracellular Na + regulation in cardiac myocytes. Cardiovasc. Res. 57, 897-912 https://doi.org/10.1016/S0008-6363(02)00656-9

Bers DM (2008): Calcium cycling and signaling in cardiac myocytes. Annu. Rev. Physiol. 70, 23-49 https://doi.org/10.1146/annurev.physiol.70.113006.100455

Blachley JD, Hill JB (1981): Renal and electrolyte disturbances associated with cisplatin. Ann. Intern. Med. 95, 628-632 https://doi.org/10.7326/0003-4819-95-5-628

Bugarčić ŽD, Bogojeski J, Petrović B, Hochreuther S, van Eldik R (2012): Mechanistic studies on the reactions of platinum(II) complexes with nitrogen- and sulfur-donor biomolecules. Dalton. Trans. 41, 12329-12345

https://doi.org/10.1039/c2dt31045g

Cheng PW, Liu SH, Hsu CJ, Lin-Shiau SY (2005): Correlation of increased activities of $\mathrm{Na}+\mathrm{K}+-$ ATPase and $\mathrm{Ca} 2+-\mathrm{ATPase}$ with the reversal of cisplatin ototoxicity induced by $\mathrm{D}$-methionine in guinea pigs. Hear. Res. 205, 102-109

https://doi.org/10.1016/j.heares.2005.03.008

Dasari S, Tchounwou PB (2014): Cisplatin in cancer therapy: Molecular mechanisms of action. Eur. J. Pharmacol. 740, 364-378 https://doi.org/10.1016/j.ejphar.2014.07.025

De Feo CJ, Aller SG, Siluvai GS, Blackburn NJ, Unger VM (2009): Three-dimensional structure of the human copper transporter hCTR1. Proc. Natl. Acad. Sci. USA 106, 4237-4242 https://doi.org/10.1073/pnas.0810286106

Demkow U, Stelmaszczyk-Emmel A (2013): Cardiotoxicity of cisplatin-based chemotherapy in advanced non-small cell lung cancer patients. Respir. Physiol. Neurobiol. 187, 64-67 https://doi.org/10.1016/j.resp.2013.03.013

Dieckmann KP, Struss WJ, Budde U (2011): Evidence for acute vascular toxicity of cisplatin-based chemotherapy in patients with germ cell tumour. Anticancer Res. 31, 4501-4505

El-Awady el-SE, Moustafa YM, Abo-Elmatty DM, Radwan A (2011): Cisplatin-induced cardiotoxicity: Mechanisms and cardioprotective strategies. Eur. J. Pharmacol. 650, 335-341

El-Sawalhi MM, Ahmed LA (2014): Exploring the protective role of apocynin, a specific NADPH oxidase inhibitor, in cisplatin-induced cardiotoxicity in rats. Chem. Biol. Interact. 207, 58-66 https://doi.org/10.1016/j.cbi.2013.11.008

Ferroni P, Della-Morte D, Palmirotta R, McClendon M, Testa G, Abete P, Rengo F, Rundek T, Guadagni F, Roselli M (2011): Platinum-based compounds and risk for cardiovascular toxicity in the elderly: role of the antioxidants in chemoprevention. Rejuvenation Res. 14, 293-308 https://doi.org/10.1089/rej.2010.1141

Frezza M, Hindo S, Chen D, Davenport A, Schmitt S, Tomco D, Dou QP (2010): Novel metals and metal complexes as platforms for cancer therapy. Curr. Pharm. Des. 16, 1813-1825 https://doi.org/10.2174/138161210791209009

Giaccone G (2000): Clinical perspectives on platinum resistance. Drugs 59, 9-17 https://doi.org/10.2165/00003495-200059004-00002

Galanski M, Keppler BK (1995): Synthesis and characterization of new ethylenediamine platinum(IV) complexes containing lipophilic carboxilate ligands. Met. Based Drugs 2, 57-63 https://doi.org/10.1155/MBD.1995.57

Hall MD, Okabe M, Shen DW, Liang XJ, Gottesman MM (2008): The role of cellular accumulation in determining sensitivity to platinum-based chemotherapy. Annu. Rev. Pharmacol. Toxicol. 48, 495-535 https://doi.org/10.1146/annurev.pharmtox.48.080907.180426 
Herrmann J, Yang EH, Iliescu CA, Cilingiroglu M, Charitakis K, Hakeem A, Toutouzas K, Leesar MA, Grines CL, Marmagkiolis K (2016): Vascular toxicities of cancer therapies: the old and the new--an evolving avenue. Circulation 133, 1272-1289 https://doi.org/10.1161/CIRCULATIONAHA.115.018347

Higgins AY, O'Halloran TD, Chang JD (2015): Chemotherapyinduced cardiomyopathy. Heart Fail. Rev. 20, 721-730 https://doi.org/10.1007/s10741-015-9502-y

Howell SB, Safaei R, Larson CA, Sailor MJ (2010): Copper transporters and the cellular pharmacology of the platinumcontaining cancer drugs. Mol. Pharmacol. 77, 887-894 https://doi.org/10.1124/mol.109.063172

Johnson WT, Newman SM Jr (2007): Hearts in adult offspring of copper-deficient dams exhibit decreased cytochrome c oxidase activity, increased mitochondrial hydrogen peroxide generation and enhanced formation of intracellular residual bodies. J. Nutr. Biochem. 18, 97-104 https://doi.org/10.1016/j.jnutbio.2006.03.005

Johnstone TC, Suntharalingam K, Lippard SJ (2016): The next generation of platinum drugs: targeted $\mathrm{Pt}(\mathrm{II})$ agents, nanoparticle delivery, and Pt(IV) prodrugs. Chem. Rev. 116, 3436-3486 https://doi.org/10.1021/acs.chemrev.5b00597

Kadikoylu G, Bolaman Z, Demir S, Balkaya M, Akalin N, Enli Y (2004): The effects of desferrioxamine on cisplatin-induced lipid peroxidation and the activities of antioxidant enzymes in rat kidneys. Hum. Exp. Toxicol. 23, 29-34 https://doi.org/10.1191/0960327104ht413oa

Katz AI (1986): Distribution and function of classes of ATPases along the nephron. Kidney Int. 29, 21-31 https://doi.org/10.1038/ki.1986.4

Kim BE, Turski ML, Nose Y, Casad M, Rockman HA, Thiele DJ (2010): Cardiac copper deficiency activates a systemic signaling mechanism that communicates with the copper acquisition and storage organs. Cell Metab. 11, 353-363 https://doi.org/10.1016/j.cmet.2010.04.003

Kounis NG, Cervellin G, Lippi G (2016): Cisplatin-induced bradycardia: Cardiac toxicity or cardiac hypersensitivity and Kounis syndrome? Int. J. Cardiol. 202, 817-818 https://doi.org/10.1016/j.ijcard.2015.10.027

Kucharz J, Michalowska-Kaczmarczyk A, Zygulska AL, Wojtak J, Pawlik W, Herman RM, Krzemieniecki K (2016): Bradycardia as a rare symptom of cisplatin cardiotoxicity: A case report. Oncol. Lett. 11, 2297-2299 https://doi.org/10.3892/ol.2016.4195

Ma H, Jones KR, Guo R, Xu P, Shen Y, Ren J (2010): Cisplatin compromises myocardial contractile function and mitochondrial ultrastructure: role of endoplasmic reticulum stress. Clin. Exp. Pharmacol. Physiol. 37, 460-465 https://doi.org/10.1111/j.1440-1681.2009.05323.x

Mao S, Medeiros DM, Wildman RE (1998): Cardiac hypertrophy in copper-deficient rats is owing to increased mitochondria. Biol. Trace. Elem. Res. 64, 175-184 https://doi.org/10.1007/BF02783334

Medici S, Peana M, Nurchi VM, Lachowicz JI, Crisponi G, Zoroddu MA (2015): Noble metals in medicine: Latest advances. Coord. Chem. Rev. 284, 329-350 https://doi.org/10.1016/j.ccr.2014.08.002

Meinardi MT, Gietema JA, van der Graaf WT, van Veldhuisen DJ, Runne MA, Sluiter WJ, de Vries EG, Willemse PB, Mulder $\mathrm{NH}$, van den Berg MP, et al. (2000): Cardiovascular morbidity in long-term survivors of metastatic testicular cancer. J. Clin. Oncol. 18, 1725-1732 https://doi.org/10.1200/JCO.2000.18.8.1725

Nath R (1997): Copper deficiency and heart disease: molecular basis, recent advances and current concepts. Int. J. Biochem. Cell. Biol. 29, 1245-1254 https://doi.org/10.1016/S1357-2725(97)00060-5

Oehmichen M, Pedal I, Schmidt V, Schlote W (1986): Form variants of globular hyaline microthrombi. Light microscopy, immunohistochemical and scanning and transmission electron microscopy observations. Z. Rechtsmed. 97, 29-40

Pai VB, Nahata MC (2000): Cardiotoxicity of chemotherapeutic agents: incidence, treatment and prevention. Drug Saf. 22, 263-302 https://doi.org/10.2165/00002018-200022040-00002

Perić T, Jakovljević VLj, Zivkovic V, Krkeljic J, Petrović ZD, Simijonović D, Novokmet S, Djuric DM, Janković SM (2012): Toxic effects of palladium compounds on the isolated rat heart. Med. Chem. 8, 9-13 https://doi.org/10.2174/157340612799278612

Saad SY, Najjar TA, Alashari M (2004): Role of non-selective adenosine receptor blockade and phosphodiesterase inhibition in cisplatin-induced nephrogonadal toxicity in rats. Clin. Exp. Pharmacol. Physiol. 31, 862-867 https://doi.org/10.1111/j.1440-1681.2004.04127.x

Shattock MJ, Ottolia M, Bers DM, Blaustein MP, Boguslavskyi A, Bossuyt J, Bridge JH, Chen-Izu Y, Clancy CE, Edwards A, et al. (2015): $\mathrm{Na}+\mathrm{Ca} 2+$ exchange and $\mathrm{Na}+\mathrm{K}+$-ATPase in the heart. J. Physiol. 593, 1361-1382 https://doi.org/10.1113/jphysiol.2014.282319

Trajković S, Dobrić S, Jaćević V, Dragojević-Simić V, Milovanović Z, Dordević A (2007): Tissue-protective effects of fullerenol $\mathrm{C} 60(\mathrm{OH}) 24$ and amifostine in irradiated rats. Colloids Surf. B Biointerfaces 58, 39-43 https://doi.org/10.1016/j.colsurfb.2007.01.005

Wang J, He D, Zhang Q, Han Y, Jin S, Qi F (2009): Resveratrol protects against Cisplatin-induced cardiotoxicity by alleviating oxidative damage. Cancer. Biother. Radiopharm. 24, 675-680 https://doi.org/10.1089/cbr.2009.0679

Yeh ET, Tong AT, Lenihan DJ, Yusuf SW, Swafford J, Champion C, Durand JB, Gibbs H, Zafarmand AA, Ewer MS (2004): Cardiovascular complications of cancer therapy: diagnosis, pathogenesis, and management. Circulation 109, 3122-3131 https://doi.org/10.1161/01.CIR.0000133187.74800.B9

Yousef MI, Saad AA, El-Shennawy LK (2009): Protective effect of grape seed proanthocyanidin extract against oxidative stress induced by cisplatin in rats. Food Chem. Toxicol. 47, $1176-1183$ https://doi.org/10.1016/j.fct.2009.02.007

Received: June 1, 2017

Final version accepted: January 18, 2018 